\title{
Study of maternal outcome in emergency peripartum hysterectomy at a tertiary hospital
}

\author{
Varalakshmi K.*, Radha Rastogi, Neha Choudhary
}

Department of Obstetrics and Gynecology, Panna Dhaya Zanana Hospital, R.N.T. Medical College, Udaipur, Rajasthan, India

Received: 23 September 2017

Accepted: 27 October 2017

\section{*Correspondence:}

Dr. Varalakshmi K.,

E-mail: varshakp389@gmail.com

Copyright: (C) the author(s), publisher and licensee Medip Academy. This is an open-access article distributed under the terms of the Creative Commons Attribution Non-Commercial License, which permits unrestricted non-commercial use, distribution, and reproduction in any medium, provided the original work is properly cited.

\begin{abstract}
Background: Emergency peripartum hysterectomy is an indispensable part of the obstetricians' armamentarium. In no other gynecological or obstetrical surgery, is the surgeon in as much a dilemma as when deciding to resort to an emergency hysterectomy. On one hand, it is the last resort to save a woman's life and on the other hand, her reproductive capability is sacrificed. Many times, it is a very difficult decision and requires good clinical judgment. Objective of present study was to study the cases of emergency peripartum hysterectomy performed in tertiary care center to estimate the incidence, indications, and maternal outcome following the procedure.

Methods: All cases of peripartum emergency hysterectomy that were performed in our hospital from January 2015 to June 2016 were reviewed and evaluated in terms of the incidence, indications, and the associated complications.

Results: During the study period there were 28 emergency peripartum hysterectomies out of 28215 deliveries giving an incidence of $0.10 \%$. rupture uterus was the Commonest indication contributing to 13 cases. Septicemia was the common post operative complication associated. There were 4 maternal deaths in our study.

Conclusions: Emergency peripartum hysterectomy though a rare operation, still remains a life- saving procedure with which every obstetrician must be conversant. regular antenatal care, identification of high- risk cases, and prompt referral can reduce the incidence of this operation. Peripartum hysterectomy will always remain an essential life saving surgery for the mother at cost of their uterus and when performed in indicated cases at right time will help in bringing down maternal mortality.
\end{abstract}

Keywords: Atonic PPH, Maternal mortality, Peripartum hysterectomy, Rupture uterus

\section{INTRODUCTION}

Emergency Peripartum Hysterectomy is an indispensable part of the obstetricians' armamentarium. ${ }^{1,2}$ In no other gynecological or obstetrical surgery, is the surgeon in as much a dilemma as when deciding to resort to an emergency hysterectomy. On one hand, it is the last resort to save a woman's life and on the other hand, her reproductive capability is sacrificed. Many times it is a very difficult decision and requires good clinical judgment. $^{3}$
Although the incidence of peripartum hysterectomy is low, it represents a major operation in modern obstetrics being associated with a high rate of morbidity and mortality. ${ }^{4}$

Originally the indications included uterine sepsis after prolonged labor, atonic uterus or uncontrollable hemorrhage from placental site, cancer of the cervix, extensive atresia of the vagina preventing discharge of lochia, cases of ruptured uterus where suturing would be unsafe, uterine fibroids and tuberculosis. ${ }^{5}$ 
Uterine rupture is an uncommon complication of pregnancy associated with potentially catastrophic consequences for both mother and baby. The nulliparous uterus has been described as being 'virtually immune to rupture', especially before the onset of contractions. ${ }^{6}$ Risk factors for uterine rupture in antepartum period are caesarean section, hysterotomy, myomectomy, placenta percreta, mullerian anomalies of uterus, previous difficult uterine curettage complicated by perforation.

The most common risk factors for intrapartum rupture in an unscarred uterus are grand multiparity, fetal malpresentation, such as unrecognised brow, face and shoulder presentation; cephalopelvic disproportion; and oxytocin augmentation in multiparous women. Less common risk factors are assisted breech delivery, instrumental delivery tumours obstructing the birth canal and pelvic deformity. ${ }^{7}$

Uterine atony and rupture have been overtaken by abnormal placentation in many studies. this is not only because of improved conservative management of uterine atony and a reduced incidence of uterine rupture due to the extensive use of the lower uterine segment incision in preference to the upper uterine segment incision for caesarean section, but also because of an actual increase in the incidence of morbidly adherent placenta.

other factors which are contributing are advanced maternal age, multiparity, multiple gestation and gestational diabetes. ${ }^{8}$ The risk factors for abnormal placcentation include scarred uterus owing to previous cesarean section, myomectomy, dilatation and curettage, multiparty and older age group. ${ }^{9}$

Regarding maternal outcome, in developed countries uterine rupture rarely results in maternal death but may have significant morbidity including hypovolemic shock, acute renal failure, complications of massive blood transfusion, Adult Respiratory Distress Syndrome, disseminated intravascular coagulation, peripartum hysterectomy, urologic injury and post-op complications like thromboembolism and infections. In less developed countries, haemorrhage due to uterine rupture is an important cause of maternal mortality. ${ }^{10,11}$

\section{METHODS}

It was Retrospective and prospective study. The study was conducted on cases of peripartum emergency hysterectomy performed at Pannadhaya Zanana Hospital RNT Medical College, Udaipur, during the period from $1^{\text {st }}$ January 2015 to $30^{\text {th }}$ June 2016 . Studied with respect to the incidence of emergency hysterectomy in our hospital, Relationship between various causes of emergency hysterectomy, complications following the procedure and Incidence of maternal mortality rates following emergency hysterectomy.

\section{Inclusion criteria}

- Patients who underwent peripartum hysterectomy either immediately or within forty-two days of vaginal or cesarean delivery

- Peripartum hysterectomy performed after 28 weeks of gestational age were taken.

\section{Exclusion criteria}

- Cases of hysterectomy performed before 28 weeks of gestational age

- Hysterectomy performed for any gynecological condition like leiomyomas and carcinoma cervix were not included in the study.

\section{RESULTS}

The fallowing observation are based on a study of 28 cases of peripartum hysterectomy treated in Zanana Hospital, RNT Medical College, Udaipur, Rajasthan during the period from $1^{\text {st }}$ January 2015 to $30^{\text {th }}$ June 2016.

\section{Incidence}

The total number of deliveries were 28215 during the study period (January 2015 to June 2016), so the overall incidence of peripartum hysterectomy is 1 in 1007 $(0.10 \%)$. Incidence of hysterectomy following vaginal delivery found to be $0.061 \%$, whereas following caesarean incidence found to be $0.16 \%$.

Table 1: Incidence of obstetric hysterectomy.

\begin{tabular}{|ll|}
\hline Statistical data & Number \\
\hline Total Number of deliveries & 28215 \\
\hline Number of cesareans & $10198(36.14 \%)$ \\
\hline Number of vaginal deliveries & $18017(63.85 \%)$ \\
\hline $\begin{array}{l}\text { Number of peripartum hysterectomy } \\
\text { Ratio of peripartum hysterectomy } \\
\text { deliveries }\end{array}$ & 28 \\
\hline Incidence of peripartum hysterectomy & $0.10 \%$ \\
\hline $\begin{array}{l}\text { Incidence of peripatum hysterectomy } \\
\text { following caesarean }\end{array}$ & $0.16 \%$ \\
\hline $\begin{array}{l}\text { Incidence of peripatum hysterectomy } \\
\text { following vaginal deliveries }\end{array}$ & $0.061 \%$ \\
\hline
\end{tabular}

Table 2: Relation of the emergency hysterectomy with parity.

\begin{tabular}{|lll|}
\hline Parity & No. of patient & $\%$ of patient \\
\hline Primi para & 5 & 18 \\
\hline Parity 2 to 3 & 19 & 68 \\
\hline Para 4 and above & 4 & 14 \\
\hline Total & 28 & 100 \\
\hline
\end{tabular}

Table 2 shows relation of obstetric hysterectomy with parity. According to above table $68 \%$ of the patients were 
para 2 and para 3. $14 \%$ were para 4 and above and $18 \%$ were primi.

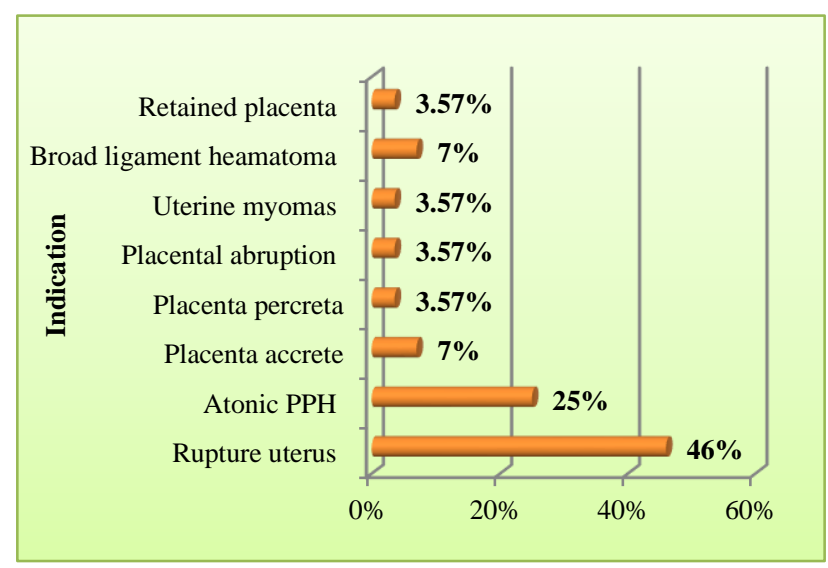

Figure 1: Indication of emergency peripartum hysterectomy.

Figure 1 explains the most common indication for peripartum hysterectomy in our study was rupture uterus (46\%) followed by postpartum hemorrhage (25\%). In 3 cases hysterectomy was done due to morbidly adherent placenta. In 2 cases (7\%) formation of broad ligament hematoma was the indication for peripartum hysterectomy. Multiple fibroid leading to uncontrollable bleeding was treated by hysterectomy in one case. Retained placenta necessitate the emergency hysterectomy in one patient i.e. (3.57\%).

Table 3: Causes of rupture uterus.

\begin{tabular}{|c|c|c|}
\hline Causes of rupture uterus & $\begin{array}{l}\text { No. of } \\
\text { patients }\end{array}$ & $\begin{array}{l}\% \text { of } \\
\text { patient }\end{array}$ \\
\hline \multicolumn{3}{|l|}{ Rupture of unscared uterus due to } \\
\hline Prolonged labour & 5 & \multirow{4}{*}{69.2} \\
\hline $\mathrm{CPD}$ & 2 & \\
\hline Fetal anomalies & 1 & \\
\hline Grand multipara & 1 & \\
\hline $\begin{array}{l}\text { Non repairable scar rupture due } \\
\text { to previous cesarean }\end{array}$ & 4 & 30.8 \\
\hline
\end{tabular}

Table 3 shows the cause of rupture uterus. Spontaneous Rupture due to prolonged labour was the commonest cause followed by dehiscence of previous scared uterus. In this series there were 13 cases of rupture uterus out of which 4 cases were due to scar dehiscence of previous cesarean sections which was unrepairable, 5 cases of prolonged labour. One case was due to fetal anomaly (hydrocephalous) with malpresentation. One case was due to transverse lie with impacted shoulder with CPD these cases were handled by Dai prior to admission. Other case of CPD with obstructed labour lead to rupture as a sequel. One case was seen in grand multipara women with inadvertent use of oxytocin for induction of labour. Out of 13 cases 8 cases underwent total hysterectomy and in 5 patients underwent subtotal hysterectomy.
In present series subtotal hysterectomy was performed in 9 cases $(32 \%)$ and Total hysterectomy in $19(68 \%)$ cases.

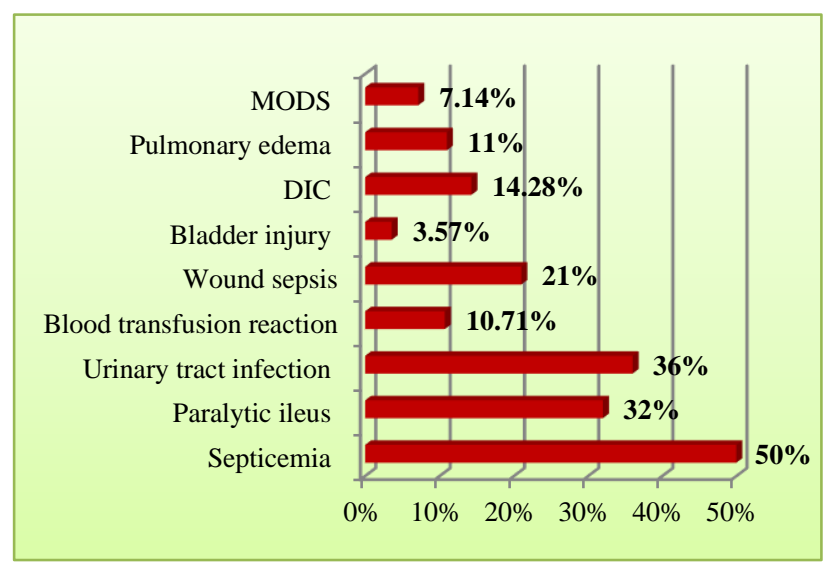

Figure 2: Post-operative complication.

Figure 2 shows Graph of postoperative complication in patients who undergone emergency peripartum hysterectomy. In present study most common complication was septicemia that occurred in 14 cases $(50 \%)$ followed by urinary tract infection in 10 cases. wound sepsis occurred in 6 patients $(21 \%)$ blood transfusion reaction occurred in 3 cases. One patient had bladder injury and same was repaired during surgery. 4 patients went into DIC, two developed pulmonary edema and 2 patients had multiorgan dysfunction due to irreversible hemorrhagic shock. All patients were admitted in ICU for proper postoperative care.

Table 4: Duration of stay in hospital.

\begin{tabular}{|lll|}
\hline Duration & No. of patient & $\%$ of patient \\
\hline$<10$ days & 13 & 46.42 \\
\hline 10 to 20 days & 9 & 32.14 \\
\hline Above 20 days & 2 & 7.14 \\
\hline Expired & 4 & 14.28 \\
\hline Total & 28 & 100 \\
\hline
\end{tabular}

\section{Maternal outcome}

In present series 4 maternal death out of 28 cases occurred, giving an incidence of $14.28 \%$.

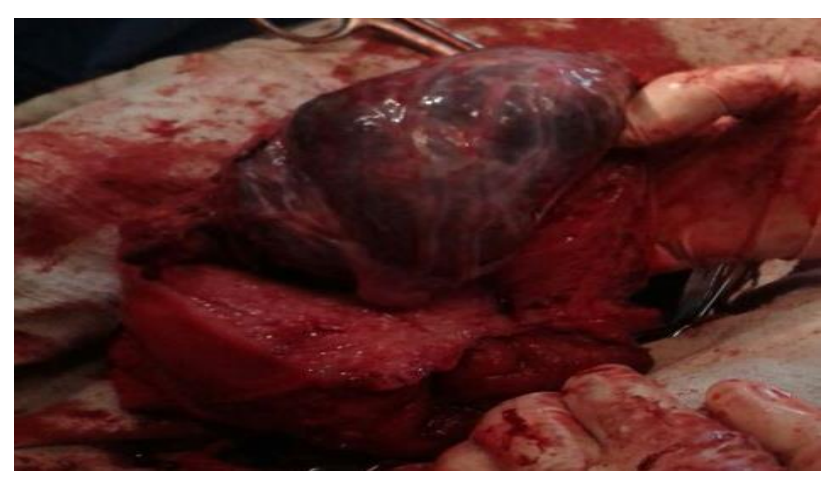

Figure 3: Morbidly adherent placenta. 


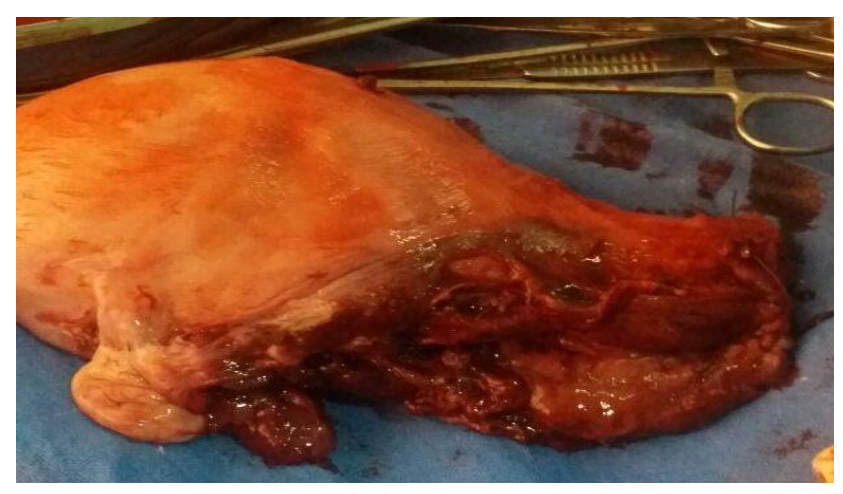

Figure 4: Rupture uterus extending to lateral wall with broad ligament hematoma in multigravida patient

\section{DISCUSSION}

In the present study incidence was $0.10 \%$. Incidence of emergency hysterectomy depends on number of factors like education status, availability of antenatal and medical care, socio economic status and nutritional status, working pattern of traditional birth attendants, fertility pattern and means of communication hence incidence is likely to be different at different places, because of variability of condition. Incidence of peripartum hysterectomy corresponds to the studies by various authors like wani et al $0.14 \%$, Dobroslawa et al $0.12 \%$, Nooren et al $0.17 \% .^{12-14}$ Higher incidence was reported by other authors like Amudha et al $1.01 \%$, Lovina et al $0.87 \%$ and Rajyshree et al $0.54 \% .{ }^{15-17}$ Nohira et al $0.03 \%$, Vijayani et al $0.07 \%$ and Swati et al $0.047 \%$ reported less incidence of peripartum hysterectomy. ${ }^{18-20}$

Higher incidence in our study was due to poor antenatal care, poor transportation, lack of education, anemia, multiparity, obstructed labour, previous caesarean section. The association between the incidences of peripartum hysterectomy with a history of previous CS is mainly because of the occurrence of morbidly adherent placenta.

In our series commonest parity was para 2 and para 3 , the main cause of peripartum hysterectomy in these parities was due to atonic PPH and rupture uterus. Similar observation was seen in Swati et al, where $17.2 \%$ were primi, $10.4 \%$ were grand multipara, with maximum cases having parity of 2 and $3(72.4 \%) .{ }^{20}$ High association of multiparity was also seen in study done by Wakhloo A et al with $82.5 \%$ in multiparity. ${ }^{21}$ In Dobroslawa et al study observed $92.31 \%$ to be multiparous and $7.6 \%$ were primipara. ${ }^{13}$ High parity was mainly due to early marital age group and short birth interval.

In present series rupture uterus was the principle indication. All 13 cases were multiparous out of which one patient was grand multiparous. All the patient belong to age group of 20 to 35 years. Except for 4 cases with previous caesarean all other patient had previous normal vaginal delivery. $69 \%$ patients were from rural area who were brought in prolonged obstructed labour. History of intervention in the form of pressure on abdomen, manipulation by para medical staffs was present in majority of cases. Out of 13 cases 8 had no antenatal care and admitted as an emergency cases.

Rupture uterus was also the most important indication for emergency hysterectomy in other series like Nohira $\mathrm{T}$ et al i.e. $38.5 \%$, Nooren et al rupture uterus accounted for $50 \%$ cases, Wakhloo et al $37.5 \%$ and Agarwal S et al found $22.22 \%$ of uterine rupture as indication of emergency hysterectomy. ${ }^{14,18,20,21}$ In Wani et al series also the main indication was life threatening hemorrhage due to uterine rupture. ${ }^{12}$

It is obvious from the above observation that the incidence of rupture uterus in our series was high. There is significant need for improvement in antenatal services, transport facilities literacy and family planning services. in developing countries like India condition are entirely different due to grand multiparity, lack of antenatal care and unsupervised labour at home and woman in labour are brought to hospital's from miles away after hours of prolonged labour hence rupture of uterus is still a live problem for us and this is main indication for hysterectomy. Atonic postpartum hemorrhage was second most common cause of emergency hysterectomy in present series. Atonic PPH necessitated hysterectomy in 7 cases i.e. $25 \%$. Out of 7 cases who had hysterectomy for atonic $\mathrm{PPH}$, five patients were multiparous and remaining two patients were primipara. Out of these 7 cases five came after the prolonged labour. PPH is unpredictable in onset, duration and etiology and it remains a major lifethreatening complication of any delivery. The incidence of atonic PPH has declined relatively over the decades due to the increased success of treatment with uterotonic agents, embolization and better surgical procedures. However, this largely preventable indication for peripartum hysterectomy continues to predominate in developing countries due to lack of proper facilities and delayed patient admission from distant areas. Emergency hysterectomy had to be under taken when other methods of treatment failed to save their lives. Out of 7 cases of atonic PPH in 5 cases B-lynch suturing was done before proceeding to hysterectomy, internal iliac artery ligation was done in 4 patients. In Jayachawla et al, Vijarani et al and Rathod et al found atonic PPH common indication for periaprtum hysterectomy. ${ }^{19,22,23}$

Out of 28 cases of emergency hysterectomy 3 cases were due to morbidly adherent placenta. Two were because of accrete and one case was done due to percreta. In all of 3 cases severe PPH occurred, the bleeding continued inspite of oxytocin, ergometrine, prostaglandin, blood transfusion so subtotal hysterectomy was under taken, following LSCS in these cases accounting for $10.57 \%$. While in Dobroslawa et al placental pathology accounted for $44.4 \%$ as an Indications for hysterectomy, Swati et al series placenta accreta was the primary indication for 
peripartum hysterectomy and accounted for $38.88 \% .{ }^{13,20}$ Placenta previa with or without associated accreta, is becoming the most common indication for hysterectomy. This is secondary to the rising incidence of conditions associated with increasing numbers of women previously delivered by cesarean section.

Two cases of broad ligament hematoma were found in present study group for which peripartum hysterectomy was done. Both the patients were multigravida delivered vaginally and were referred from periphery for postpartum hemorrhage with shock. After failure of medical management for $\mathrm{PPH}$, laprotomy was performed in view of rupture uterus, there found broad ligament hematoma with rupture of lateral wall of uterus and peripartum hysterectomy performed for the same. broad ligament hematoma even though a rare and dreadful complication should always be kept in mind in cases which are non responsive to standard lines of treatment and where no obvious cause for shock is found by an obstetrician to prevent loss of life. ${ }^{24}$

Wani et al found 7 cases of broad ligament hematoma, Lamba $\mathrm{J}$ et al observed $6.2 \%$ cases of broad ligament hematoma accounting for peripartum hysterectomy. ${ }^{3,12}$

Subtotal hysterectomy is a much faster and technically safer procedure for desperately ill patients and those who may have massive adhesions over the lower uterine segment involving the urinary bladder. The choice between subtotal and total hysterectomy has long been debated. Total hysterectomy is the preferred surgical method due to the potential risk of malignancy developing in the cervical stump. However, proponents of subtotal hysterectomy report lesser blood loss, reduced operating time and reduced intra and postoperative complications. ${ }^{25}$

Ironically, in the present study, there was a higher incidence of intraoperative and postoperative complications in the subtotal hysterectomy group which may be explained by the fact that it was carried out in moribund patients to reduce the operative time. The final decision to perform subtotal or total hysterectomy should be influenced by patient's condition. Hence, while total abdominal hysterectomy is a desirable procedure, subtotal hysterectomy may be a better choice in certain conditions where surgery needs to be completed in a shorter time. ${ }^{16}$

In Wani et al series and in Amudha et al study most women underwent total hysterectomy, while in Sameena et al $56.3 \%$ patients required subtotal hysterectomy than $43.7 \%$ of total abdominal hysterectomy. ${ }^{12,15,26}$

Placenta accreta was an independent risk factor for bladder damage and also a risk factor for further surgery. This emphasizes that consideration of the cause of the associated haemorrhage is important when these women are managed.
Other authors also reported similar observation like in Wani et al series. ${ }^{12}$ The common post operative complications were febrile morbidity $(15.68 \%)$, wound sepsis $(10.78 \%)$, pneumonia $(8.82 \%)$, coagulopathy $(5.88 \%)$, cuff cellulitis and vesicovaginal fistula $(1.96 \%$ each).

In Amudha et al out of 28 cases during the post operative period 10 patient were febrile, wound infection occurred in $13.8 \%$, DIC was found in 8 cases $27.6 \%, 3$ of them had cute kidney injury and septicemia each. ${ }^{15}$

In western countries like Dobroslwa et al series complications of the lower part of the urinary tract during hysterectomy were observed in $7(13.5 \%)$ patients. Vesicovaginal fistula was found in $1(1.9 \%)$ woman on postoperative day 10 after hysterectomy performed and 1 $(1.9 \%)$ case of ureter injury (left) was noted. Reoperation after peripartum hysterectomy was required in $4(7.7 \%)$ patients, including 2 after vaginal birth. Three such cases were noted after total hysterectomy, including 1 case of amputation of the uterine corpus. Symptoms of hypovolemic shock were noted in all women who underwent reoperation, and 2 who required admission to the ICU. ${ }^{13}$

In present study half of the patients stayed in hospital for $<10$ days with the mean duration of 12.2 days. prolonged stay in hospital was mainly due to wound sepsis, anemia, febrile illness. Two patients had stayed in hospital for more than 20 days one case was because of bladder repair, one case of severe wound sepsis which needed routine dressing.

All the maternal deaths were in unbooked or referred patients who were brought in a hemodynamically unstable condition with varying degrees of shock. There is a relationship between the decisions to perform the hysterectomy, the amount of blood loss and the likelihood that the hysterectomy will be complicated by coagulopathy, severe hypovolemia, tissue hypoxia, hypothermia and acidosis which further compromises the patient status. Proper timing and meticulous care may reduce or prevent maternal complications. ${ }^{3}$

It is obvious that incidence of maternal mortality can be lowered with availability of good antibiotics, blood and blood products, competent anaesthesilogist and surgeon. This also indicates need for improvement in transport services, antenatal care, family planning services, and female literacy and awareness regarding the knowledge of hospital delivery.

Like in our series maternal death i.e $14.28 \%$ in Swati et al series also rate was in higher side i.e 19.4\%, Lower rates were seen Dobroslawa et al i.e. 1.9\%, Rajyashree et al $5.7 \%$ and Ahmad $S$ et al following emergency hysterectomy i.e. $3 \%$, and the cause of death was related to complications like shock, septicemia and disseminated intravascular coagulation. ${ }^{13,17,27}$ 


\section{CONCLUSION}

Peripartum hysterectomy is a life saving obstetric surgical procedure that has potentially devastating consequences. The worldwide increase in caesarean section rates may lead to a rise in the number of peripartum hysterectomies required in the future because of increased chances of scar dehiscence and morbidly adherent placenta and Thus, there is a need for institutions to reassess their indication for first cesarean section to decrease the incidence of cesarean sections.

Due to the complexity of the surgery and life threatening complication involvement of an experienced obstetrician/ pediatrician/ anesthetist at an early stage is desirable. Since good ICU care and adequate blood transfusion are needed facilities for these should be kept in mind.

Antenatal identification of high risk patients, proper management of second and third stage of labor and emergency preparedness are important in decreasing the rate of peripartum hysterectomy and improving the maternal outcome. Risk of rupture of uterus or placental abnormalities and PPH should be kept in mind in previously sectioned patients. Timely reference with documentation from periphery of these high risk patients will certainly improve the outcome.

Also, there is a need for more effective implementation of family welfare and reproductive health measures in the developing nations to reduce the incidence of life threatening obstetric complications.

Peripartum hysterectomy will always remain an essential life saving surgery for the mother at cost of their uterus and when performed in indicated cases at right time will help in bringing down maternal mortality.

Funding: No funding sources Conflict of interest: None declared

Ethical approval: The study was approved by the Institutional Ethics Committee

\section{REFERENCES}

1. Sturdee DW, Rushton DL. Cesarean and post partum hysterectomy. Br J Obstet Gynecol. 1986;93:270-74.

2. Mantri L, Maheshwari K, Chandra. Emergency Hysterectomy a ten years review. J Obstet Gynecol India. 1995;43:936-9.

3. Lamba J, Gupta S. Role of emergency hysterectomy in modern obstetrics. JK Sci. 2012;14(1):22.

4. Rossi AC, Lee RH, Chmait RH. Emergency postpartum hysterectomy for uncontrolled postpartum bleeding. Obstet Gynecol. 2010;115:63744.

5. Glaze S, Ekwalanga P, Roberts G, Lange I, Birch C. Peripartum Hysterectomy: 1999 To 2006. Obstet Gynecol. 2008;111:732-8.
6. O'Driscoll K, Meagher D, Robson M. Active Management of Labour: The Dublin Experience. $4^{\text {th }}$ ed. London: Mosby; 2004.

7. Ofir K, Sheiner E, Levy A, Katz M, Mazor M. Uterine rupture: risk factors and pregnancy outcome. Am J Obstet Gynecol. 2003;189:1042-6.

8. Kwee ML, Bots GHA, Visser, ruinse HW. Emergency peripartum hysterectomy: a prospective study in the Netherlands. Euro J Obstet Gynecol Reprod Biol. 2006;124(2):187-192.

9. Ara S, Umbreen, Fouzia. Emergency obstetric hysterectomy. Professional Med J. 2015;22(1):100-5.

10. Kwee A, Bots ML, Visser GH, Bruinse HW. Uterine rupture and its complications in Netherlands: a prospective study. Eur J Obstet Gynecol Reprod Biol. 2006;128:257-61.

11. Malik HS. Frequency predisposing factors and fetomaternal outcome in uterine rupture. J Coll Physicians Surg Pak. 2006;16:472-5.

12. Wani S, Fareed P, Gull Y, Mahajan N. Emergency peripartum hysterectomy: incidence, indications and fetomaternal outcome in a tertiary care hospital. Int $\mathbf{J}$ Curr Res Rev. 2016 Feb 1;8(3):7.

13. Sikora-Szczęśniak DL, Szczęśniak G, Szatanek M, Sikora W. Clinical analysis of 52 obstetric hysterectomies. Ginekologia Polska. 2016;87(6):4606.

14. Nooren M, Nawal R. Obstetric hysterectomy: a life saving emergency. Indian $J$ Med Sci. 2013;67(5\&6):2013.

15. Sarojini A. Clinical study of emergency peripartum hysterectomy postpartum hemorrhage. International journal of reproduction, contraception, obstetrics and gynecology. Int J Reprod Contracept Obstet Gynecol 2016 Apr; 5(4):1171-3.

16. Lovina SM. Machado, emergency peripartum hysterectomy: incidence, indications, risk factors and outcome. N Am J Med Sci. 2011;3(8):358-361.

17. Sharma R, Shaheen, Pathak J. Peripartum hysterectomy review of 70 cases. South Asian Federation Obstet Gynecol. 2009;1(2):19-21.

18. Nohira $T$, Onodera $T$, Isaka $K$. Emergency postpartum hysterectomy: incidence, trends, indications and complications. Hypertens Res Pregnancy. 2014;2:88-93.

19. Vijayan A, Saraswathi. Review of peripartum hysterectomy cases in five years. IOSR-JDMS. 2015;14(10):1-4.

20. Agrawal S. Peripartum hysterectomy in a teaching hospital in India. Asian J Med Sci. 2014 Jul 1;4(1):59.

21. Wakhloo A, Zarfashian A, Gupta S. A study of various factors associated with peripartum hysterectomy. JK Sci. 2016;18(1).

22. Chawla J, Arora CD, Paul M, Ajmani SN. Emergency obstetric hysterectomy: a retrospective study from a teaching hospital in north india over eight years. Oman Med J. 2015 May;30(3):181-6.

23. Rathod AD, Pajai SP. Emergency obstetric hysterectomies at a tertiary referral Shri Vasantrao 
Naik Government Medical College and hospital of tribal of Yavatmal district (Maharashtra): retrospective critical analysis (6 years study). J South Asian Feder Obst Gynecol. 2015;7(2):55-60.

24. Kashika, Gaikwad H. Broad ligament hematoma after spontaneous vaginal delivery: a case report. IOSR-JDMS. 2016;15(7):52-53.

25. Chanrachakul B, Chaturachinda K, Phuspradit W, Roungsipragarn R. Cesarean and post partum hysterectomy. Int J Gynecol Obstet. 1996;54(2):109113.

26. Ashraf S, Gul Y, Malla MS, Mohi-ud-Din Regoo F. Emergency peripartum hysterectomy at a tertiary care hospital in Kashmir valley. J Evol Med Dental Sci. 2015;4(3):400-7.

27. Ahmad S, Mir I. Emergency peripartum hysterectomy: experience at apex hospital of Kashmir valley. Internet $\mathbf{J}$ Gynecol Obstet. 2006;8(2):1-4.

Cite this article as: Varalakshmi $\mathrm{K}$, Rastogi $\mathrm{R}$, Choudhary N. Study of maternal outcome in emergency peripartum hysterectomy at a tertiary hospital. Int J Reprod Contracept Obstet Gynecol 2017;6:5602-8. 